\title{
Las "Tensiones" de Carlos Martínez Moreno
}

Es indudable que Carlos Martínez Moreno es uno de los escritores más representativos de la llamada Generación uruguaya del $45 .^{1}$ Con ocho libros publicados ${ }^{2}$ ya ha ido completando una particular visión de la realidad circundante, inscrita en forma directa en el marco conflictivo latinoamericano y referida constantemente -por las pautas culturales que la enmarcan y por las referencias literarias que la significan- al esquema

${ }^{1}$ La mejor aproximación crítica a esta generación y las razones por las que se le llama del 45 es la efectuada por Emir Rodríguez Monegal en su libro Literatura uruguaya del medio siglo (Montevideo, 1966). En ese complejo trabajo, abundante en datos y anécdotas sobre las polémicas que la dividieron generacionalmente, se efectúa una completa caracterización de la obra de C.M.M. situándolo, conjuntamente con Juan Carlos Onetti, como uno de los autores más representativos del grupo que integra el propio Rodríguez Monegal en el plano crítico. Ese capítulo - "Las ficciones de Martinez Moreno" (pág. 260 a 293) recoge muchas de las sagaces observaciones adelantadas en forma casi premonitoria en 1951, cuando C.M.M. apenas había publicado algunos relatos en diarios y revistas (Número 15/16/17; julio/diciembre, 1951; Montevideo).

2 Nacido en 1917 en la ciudad de Colonia (Uruguay), Martínez Moreno em. pieza a publicar tardíamente (1960) en forma de libro muchos de sus relatos aparecidos anteriormente en publicaciones periódicas. Abogado penalista y periodista activo no se muestra originalmente muy urgido por editar sus cuentos. Sin embargo, desde 1960 a la fecha ha publicado varios volúmenes de cuentos y cuatro novelas: Los dias por vivir (Montevideo, 1960), Cordelia (Montevideo, 1961); El paredón (Barcelona, 1962); Los aborígenes (1964); La otra mitad (Mejico, 1966); Con las primeras luces (Barcelona, 1966); Los prados de la conciencia (Montevideo, 1968); Coca (Caracas, 1970). Paralejamente, en 1969, aparece en Caracas un volumen de cuentos bajo el título de "Las bebidas azules", que reúne una especie de antología personal de sus relatos ya publicados. Parte de la notoriedad que lo consagra como autor representativo de la Generación del 45 proviene de dos premios inter nacionales: "Los aborígenes" merece en el Concurso Literario convocado en 1960 por la revista "Life en español" el segundo premio; $E l$ paredón resulta accesit en el concurso de novela de la Editorial Seix-Barral en 1961. 
curopeo del que es deudor. Esa visión se ha ido cerrando en sus últimas novelas sobre temas y presupuestos adelantados en sus primeros relatos, confirmando un estilo y una serie de preocupaciones formales y temáticas que, en su caso, pueden calificarse de "tensiones" ${ }^{3}$ las que se dan entre los estrictos artificios formales y la naturaleza del lenguaje, entre la perspectiva cnfriada para analizar un sujeto y la condición original de éste hecha de pasión y violencia, entre el tema del amor y el del odio o la muerte.

Estas "tensiones" suponen auténticas contradicciones dialécticas llevadas a numerosos planos temáticos y simbólicos de la narrativa de Martínez Moreno: infancia contra madurez, pasado contra presente, una dialéctica hecha de atracción y rechazo entre Europa y América (Lus aborigenes y Coca) y aun entre partes de la misma América Latina (El Paredón). Estos "paradojales" antagonismos forman un rico y sugestivo tejido literario, cuya urdimbre encierra no sólo una absoluta originalidad, sino parte de las que pueden ser consideradas características más relevantes de la Generación del 45 , que el narrador integra.

3 Algunas tendencias críticas resaltan la importancia de valorizar la obra literaria en función de su "unidad compleja" más que por sus elementos aislados. En la medida en que esa unidad está hecha de "tensiones" (contrastes, oposiciones y aun aparentes contradicciones) ofrecerá una mayor sugestividad y calidad: los elementos enfrentados en tensión ayudan a sostener toda la estructura en una sola unidad. "Tensión suggests the internal energy, the presence of contrats and qualifications, that we associate with valuable art, in contradistinction to the monoto. nous simplicity of an inferior poem or tale", ha escrito W. Stacy Johnson en la obra colectiva "An introduction to literary criticism" (Heath; Boston, 1967; pág. 150). Del mismo modo, Robert Pen Warren en su ensayo "Pure and impure poetry" ("Selected essays"; Random House, 1943) define las características de la naturaleza de la estructura poética empezando por "las tensiones y resistencias que deben existir a diferentes niveles": "there is the tension between the rythm of the poem and the rythm of speech; between the formality of the rythm and the informality of the language; between the particular and the general, the concrete and the abstract; between the beautiful and the ugly; between ideas; between the elements involved in irony..." Más adelante propone "the poet is like the jiujitsu expert; he wins by utilizing the resistence of his cpponent, the materials of the poem. In other words, a poem, to be good, must earn itself". Thambién el novelista Carlos Fuentes ha recogido este esquema en sus recientes ensayos críticos sobre novela latinoamericana al definir a la novela "como un encuentro de resistencias". La obra de Martinez Moreno parece probar, por su complejidad, parte de este aserto. En cierto modo, su realismo y sus complicaciones intelectualizadas son los tradicionales enamigos de "la pureza del jardín" de que habla el mimo Pen Waren, algo que parece muy importante en un continente no menos llenos de "tensiones" e "impurezas", como lo es el latinoamericano hoy en dia. 


\section{INTELECTUALIZADOS Y REALISTAS CONFLICTIVOS}

En este sentido, Martínez Moreno encarna, mejor que nadie, la reacción de esa generación contra lo que él mismo llamara en 1951: "la equívoca pobreza mental de nuestra literatura, disfrazada por demasiado tiempo de estremecimiento, de confesionalismo, de fervor sensible." Una actitud que lo llevó a propugnar "una asepsia antidemagógica", entendiendo "lo demogógico en literatura como la indiscriminada sensibilidad" y que Emir Rodríguez Monegal llamara una reacción "implacable en su denuncia de lo prestigioso y poético a priori". ${ }^{4} \mathrm{El}$ rigor consiguiente que esa actitud implica lo llevó - como a otros autores de su misma generación- a inscribirse en una corriente literaria que puede ser caracterizada en su conjunto como intelectualizada, realística, conflictiva, individualista, anti-emotiva y, al mismo tiempo, como preocupada por la tensión formal y la complejidad de la estructura narrativa. Una suerte de combinación no siempre fácil de explicar y no siempre lograda con el mismo nivel.

Para entender cabalmente las "tensiones" que dividen y enriquecen al mismo tiempo esta narrativa es importante marcar algunas de estas características. Por lo pronto el intelectualismo: el modo como prima la reflexión sobre la acción, la razón sobre la pasión, la ideología sobre la pura aventura. Pese a la marcada influencia de las letras anglosajonas, especialmente la novela norteamericana de la "generación perdida", la actitud de los escritores del 45 fue la de recoger esa postura al modo como se la había_asimilado en Francia. El mensaje original de un Hemingway o un Faulkner es traducido a través de las interpretaciones que de ellos dan un Sartre o un Camus; Dos Passos entendido a través de Los caminos de la libertad. Esta tendencia analítica se da particularmente en la obra de Martínez Moreno complementaba con una amplia gama de referencias culturales que acentuan ese preferir mirar a actuar, ese "preferir pelar una banana a comérsela". como reconociera en oportunidad de publicarse El Paredón. Sus personajes se explican muchas veces literaria. mente, se iluminan con significados ya aceptados por sus cnnotaciones en el mundo de las letras o de la pintura. Notorio en Los' aborígenes, abrumador en "Ignotus", "Los prados de la conciencia" y "La pareja del museo del Prado", se llega a auto-aceptar al permitir que un personaje reflexione: "Oh Pérez, qué literario eres, serías así aun para morirte!"s En tanto el tema o los personajes circulan en un mundo en que rigen esos

\footnotetext{
4 "Las ficciones de Carlos Martinez Moneno" en revista Nümero citada.

5 Los prados de la canciencia, abundante en referencias y juegos intelectuales efectuados por un escritor durante un paseo larededor de la isla de Manhattan.
} 
valores, su intelectualización puede ser aceptada como parte de ese mundo. El problema - y su consiguiente desajuste- se plantea en obras como Coca, donde los personajes aparecen divorciados de toda intelectualidad, pero apoyados en continuas referencias culturales: Goya, William Blake, "el niño" Arthur Rimbaud, Flaubert, y donde se proponen auténticas ucronías como "si Marcel hubiera leído a Flaubert habría podido llamar el bovarysmo de Marie Louise".

Algunos críticos han señalado la importancia decisiva que puede tener para el futuro quehacer creador de Martínez Moreno este intelectualismo, especialmente cuando en relatos dinámicamente despojados de toda reflexión se gana en espontaneidad ("La fortuna de Oscar Gómez", por ejemplo). Importancia decisiva que puede resumirse, pura y simplemente, en la alternativa de ahogar su literatura o liberarla.

Básicamente intelectualizada, esa narrativa está, pese a todo, directamente conectada al realismo, superado en la dimensión tradicional latinoamericana "verista" " "eficaz". Con la excepción de un par de cuentos o algún pasaje alegórico de sus novelas, Martínez Moreno trabaja temas de la realidad circundante: "Mis temas nacen de lo que me rodea, ya se encuentre en el presente o en el pasado - ha declarado. Puede rodearme esa vida que sólo deja ver una burbuja o una espuma en la superficie y tiene todas sus madréporas hundidas en el fondo del pasado. Sobre esa vida que siento alentar a mi alrededor, real o fantasmal, a partir de esencias reales; sobre la vida que disfruto o padezco, sobre la que veo disfrutar o padecer delante de mi. Nunca he escrito sino a partir de vivencias inmediatas, jamás a partir de una ideación puramente fantástica, desasida de mi".

Esa relación con la realidad se da a través de puntos de vista netamente individualistas y subjetivos. La relación de tensión personal, de básico inconformismo subyacente, directa o indirectamente, en la novelística del 45, se traduce en fórmulas propias del novelista y nunca en la aceptación de cánones colectivos. El ejemplo de El Paredón es claro. Su compromiso con la realidad inmediata no lo llevó a propiciar un libro fácil y halagador al maniqueismo de la hora. Al contrastar dos mundos -el institucional uruguayo y el revolucionario cubano- a través de la experiencia moral de Julio Calodoro, el autor cortó por ángulos mucho más precisos que una simple división. Insertado en "una sociedad civil e inmovilista": (Uruguay) el protagonista intuye y denuncia su quietismo y desarraigo, pero no puede abrazar ingenuamente la otra alternativa que mira como ajena y sospecha cargada de violencia. "Novela de planteamientos y no una aventura beligerante que fuerce conclusiones" declaró 
el autor. Planteamientos que pueden ser dudas, exagerada lucidez o una pasión por el análisis a la que no es ajeno un trasfondo de preocupaciones éticas.

\section{TENSIÓN CULTURAL Y REVOLUCIONARIA}

Una frase pendiente de soluciones: "Pues sí, linda, ¿qué va a ser de nosotros hoy día?" — con que se cerraba Los aborigenes adelantaba la necesidad de Martínez Moreno- más allá de la del protagonista Serapio Cortés por incursionar detalladamente en "las diferencias atávicas americanas que pugnan en él, con las afinidades culturales que puede sentir por Europa"."

En El Paredón esa línea de "tensiones" culturales era retomada en el sentido anotado, aventurándose una respuesta a ese "¿qué va a ser de nosotros hoy día?" en la dirección inmovilista uruguaya: dejar que todo siga como está, una apuesta "gattopardiana" que en Coca es revertida a términos más terribles: aún sufriendo un proceso revolucionario no es posible escapar a la corrupción o a la contrarrevolución próspera que crece en el seno de la misma revolución. Novela de "los que se sirven de la revolución a la que no sirven", Coca acumula nuevas tensiones culturales a la novelística de Martínez Moreno. Le basta tomar a los protagonistas de una revolución (la boliviana de 1952) quince años después, para que las ilusiones originales aparezcan ingenuas y corrompidas, inútilmente gestadas.

En Los aborigenes el medio para enfriar el original impetu revolucionario estaba basado en revertir el pasado en el presente en el cual se vive y desde el cual se narra. El espejo del presente tiñe las imágenes del pasado que se reflejan en él con los colores de la decepción, las frustraciones y la derrota moral de la revolución. Los recuerdos del diplomático andino en la suerte de "destierro espiritual" en que vive, afectado a una embajada en Roma, se convierten en una suerte de dicotomía antagónica en que la conciencia de todo intelectual latinoamericano está dividida. La clave es sutil: reconstruir algo cuando ya se lo sabe derrotado es destruirlo dos veces. Reconstruir una revolución desde jardines romanos y con un chofer esperando en la esquina es acumular una paradoja sobre otra, una vuelta de tuerca del tiempo sobre un posible legítimo impulso original.

- Palabras con que fuera definida en oportunidad de otorgársele el premio de "Life en espñol", en 1960. 
La mirada de Martínez Moreno - se ha escrito- no es compasiva, sino acusatoria. Hay un propósito en su literatura por desnudar componendas e hipocresías, por develar simulaciones y mentiras, lugares comunes y trampeamientos. CMM acusa a sus personajes y los obliga a mirarse en esos implacables espejos del tiempo y allí queda - tensamente contrastada - su aparente frialdad y serenidad para hundir el bisturí en la realidad con su preocupación ética. Mundo del desencanto y la recón. dita frustración, el mundo de CMM puede parecer inútilmente cruel. Sin embargo, esa lucidez para condenar y ese rigor acerbamente crítico que rehuye estereotipos y mistificaciones, encierra algunas sofocadas nostalgias. Tres de ellas dan la dimensión exacta de su real pasión, más allá del esquema intelectual o cultural en que son revertidas: el amor despojado de sus corrupciones, la infancia como parte del paraíso perdido y la muerte como desnuda expresión de la vaciedad de los boatos de la vida. Amor, infancia y muerte proyectados conflictivamente en un complejo universo ético, donde la nostalgia juega el papel de la imposibilidad de su pura obtención.

\section{EL AMOR EN DESCOMPOSICIÓN}

Porque cuando Martínez Moreno aborda el tema del amor sucede lo mismo: el juego de espejos y reflejos en el tiempo se encarga de enfriar y reutralizar toda pasión posible. Las detalladas incursiones en el pasado, a partir de un presente que permanece inmóvil, le permiten - una vez más- disecar sentimientos, analizar reacciones, juzgar implacablemente desde la corrupción actual, una posible frescura original. Lo hace en " $\mathrm{La}$ última morada" indirectamente, en "Los aborigenes como una suerte de segundo plano, en "Cordelia" corrompiendo una forma del amor paternal y en $L_{a}$ atra mitad analizando sentimientos sobre un cuerpo ya muerto. Aun tocado lateralmente en la aventura cubana de Julio Calodoro en $E l$ Paredón, el amor como sentimiento aparece siempre ya corrompido, en la faz gastada y caduca del amor conyugal, en una suerte de estado de putrefacción, nunca en el entusiasmo lírico que ha generado, justamente, ese desajuste actual. Los ejemplos son numerosos: Victor y Sara rememoran en "Tenencia alterna" un pasado feliz, pero lo hacen flanqueados por los abogados que los divorcian; Primitivo Cortés en Los aborigenes trata de sùperponer sobre el rostro destrozado de su esposa Leonor un afecto original; en "El salto del tigre" se cuenta "una historia de amor en que el sentimiento va averiándose a medida que pasa de personaje". 
En "Cordelia", el hedonista Robledo que "ni siquiera tiene la grandeza de sus convicciones" como escribiera Rodriguez Monegal a su respecto, explota la memoria de su hija, corrompe una forma del amor paternal desde un presente solitario del cual únicamente en las últimas líneas podrá emerger, enancado en el frívolo plural de "las mujeres".

Pero es en La otra mitad donde Martínez Moreno redondea más perfectamente una especie de "teoría del comportamiento amoroso". Su cerrada cosmogonía axiológica sólo propone un amor viable: el que emerge ilegítimamente de "un adulterio procesional y anónimo", sin momentos "tristes o culminantes". Como contrapunto al amor adúltero, el amor conyugal está hecho de un "tejido de incoherencia, de elipsis, de asociaciones de ideas absolutamente singulares o indescifrables, con historia propia, sobre el que se comprenden y a partir del cual conversan un hombre y una mujer que ha convivido durante años". ${ }^{7}$

Es en el adulterio donde, bajo la sombra siempre presente de un marido engañado, pueden intentarse las aventuras sentimentales envueltas de una paradójica pureza. Mario y Cora viven un pequeño torbellino que tiene mucho de juego adolescente recién descubierto en la cuarentena que frisan los dos protagonistas. Parece no importar que Cora esté casada en esas páginas en que se recorren playas desiertas con el amante tomado de la mano, se mira el cielo y se descubre la espontánea primitividad de una noche pasada en un albergue. En Coca el amor de Marie Louise y el Capitán boliviano aparece también siempre superpuesto a amores originales violados: el Capitán está casado, Marie Louise mantiene un inconsciente cordón umbilical nunca cortado con su concubino.

Sin embargo, esas pasiones adulterinas están muy sofocadas, aún en sus explosiones. Su espontaneidad aparece marcada por las notas de "un amor intelectual, razonado, rescatado a los ojos de los demás, evasivo de sus peligros, comprimido en su clausura"s en el caso de La otra mitad, llegándose a confesar que estaba cubierto de "zonas que ahora me parecen viciosamente intelectuales", ${ }^{9}$ donde "nadie seducía, nadie era seducido... nadie poseía, nadie era poseído". ${ }^{10}$ En Coca un amor mucho me-

7. La otra mitad (pág. 194 y 195).

8 Ibid. p. 110. El contrapunto de este adulterio no es menos sofocado: la vida matrimonial de Cora aparece enmarcada en "un repertorio de placer limitado, voluntariamente ignorante de los abismos, con un horror mediocre e irreligioso a la concupiscencia y a la lascivia, con la sospecha de que las depravaciones se emboscan tras cualquier novedad" (pág 318).

9 lbid. p. 112

1.0 Ibid. p. 258. Esta reflexión supone reconocer en forma tardía una cobardía original que Mario Ponsetti se plantea retroactivamente al decir "¿Por qué - pienso ahora- no le pedi que se divorciara, por qué no nos insurgimos y nos publicamos, dueños de los únicos títulos que deberían valer en estas situaciones? No sé; 
nos "profesoral" que el de Mario y Cora está, sin embargo, aludido a sus significaciones literarias y pictóricas laterales: se lo entiende por lo explicado, no por lo directamente vivido. Se llegará, de este modo, a recordar la entrega de la virginidad de Marie Louise a Monsieur Vincent no como un acto de amor ingenuo en su origen, sino como la consumación de un acto con alguien "baboso de erotismo como el tísico vergonzante que era". 11

Parte de este enfriamiento intelectual y analítico proviene, una vez más, de la técnica de reconstruir el pasado desde un presente estático, de enfrentar las "tensiones" que el solo paso del tiempo provoca. Pero esa técnica tiene una fundamentación ética que en el caso de La otra mitad aparece directamente explicitada. Mario Possenti trata de reconstruir "la otra mitad" de Cora por razones éticas: "no hay derecho a desconocer al ser que amamos" reflexiona, tratando de "permutar valores de conocimiento por valores de culpabilidad". En todos sus pasos presentes se "siente culpable pcr omisión": amó a una mujer casada durante un año y al aparecer esta un dia muerta (asesinada o suicidada) junto al cadáver de su esposo, siente que no la conocía realmente. El contrapunto ético será constante: la pasión adulterina estará siempre reflejada en un espejo donde la esencia es la muerte, una muerte expresada en la sombría morgue, un cementerio, la reconstrucción literaria de atra muerte con muchos paralelos (la de la poetisa Delmira Agustini), en un permanente asordinar todas las jubilosas vivencias del pasado.

El juego de reflejos - a modo de enfrentar las reales tensiones- tiene dos claros extremos: la infancia que no siempre explica el presente y ese inevitable final de todos los mortales. Estructuralmente, Martínez Moreno propone reflejar un amor corrompido para descubrit, más que las raíces sentimentales, una razón ética. El espejo del presente se abre en dos precisos ángulos opuestos contradictoriamente: una infancia cargada de secretas añoranzas y una muerte que cierra todas las frivolidades con interrogantes que rozan la metafísica. Esta especie de triángulo estructural, abierto en su centro por el amor desgarrado, se proyecta casi inequívocamente en todas suis obras y marca la dimensión exacta de sus tensiones cerradas siempre geométricamente.

tal vez no sé "romper", por no ir contra el orden establecido y contra las tácitas conmiseraciones que él defiende" (pág. 21).

11 Coca, pág. 35. 


\section{LA AÑORANZA SECRETA DE LA INFANCIA}

Es ya casi un símbolo en la narrativa de Martínez Moreno: cargados de culpas y resentimientos, sus personajes añoran secretamente su propia infancia, edad de la que fueron expulsados en nombre de una madurez que nunca asumen justificadamente. Desde sus primeros relatos -especialmente en "Los días escolares" - se percibe un permanente contrapunto entre ese paraiso perdido y la existencia actual marcada por las coartadas, las trampas y la inevitable corrupción. En la infancia están siempre las experiencias significativas de las actitudes presentes de los protagonistas, contrastadas dramáticamente en el caso de "Los sueños buscan el mayor peligro", pero no siempre sinónimo de pureza o de un bien tristemente perdido. Rodríguez Monegal no ha dejado de señalar que "en la infancia están también la simulación, la violencia, la muerte, como anticipo de esa otra corrupción fatal que es la vida." Así, "si bien la infancia es un paraíso perdido, en el paraíso infantil no faltan el Mal, la serpiente, la promesa de una segura corrupción."

Sin embargo, a propósito de su propia infancia ha podido declarar CMM "tuve una infancia materialmente segura, podemos comenzar allí. Viví en un hogar estable y a pesar de eso dentro de esa infancia y de ese hogar me sentí perpetuamente inseguro, gratuitamente culpable. Era y soy el mayor de tres hermanos muy seguidos, y durante toda mi infan. cia crei que la mayor ambición de mis padres podría ser la de abando. narnos y reemprender una nueva vida". Esa sensación de inestabilidad está directamente novelada en La otra mifad con ribetes pesadillescos. Cora recuerda cuando se sintió absurdamente abandonada por sus padres al volver un día a su hogar y no encontrarlos por simple casualidad; amontona luego anécdotas como el episodio de "la mellada"12 e impregna a su infancia de cargas demoníacas no siempre explicables en la madurez.

También en Con las primeras luces, los mejores capítulos están referidos a la reconstrucción de la infancia de Eugenio y sus primos, donde algunos juegos como las representaciones teatrales que propicia Mariucha, se convierten en una suerte de proyección simbólica de la vida futura, en un "guignol" peligroso por lo inconscientemente premonitorio. Juegos infantiles que en El paredón (episodio del fusilamiento de las botellas) o en Coca (los juegos del balconcillo del ferrocarril entre Marie Louise y Vladimir) son también $1 \in$ presentaciones estremecidas de un futuro a vivir.

Ese volver a la infancia desde el presente que se rechaza por las derrotas que conlleva, supone un alarmado terror de la vejez, vista de pronto

29. La otra mitudl, pág. 95. 
en Con las primeras luces como un irse quedando solo "en un cuarto del que otros estuvieron sacando los muebles." Pero más aún, un rechazo de la muerte inevitable.

\section{LA MUERTE COMO "BÚSQUEDA DE ESENCIAS"}

Más claramente que en las "tensiones" del amor y la corrupción, la infancia o la madurez, Martínez Moreno recurre - a modo de verdadera constante - al tema de la muerte. La presencia de la muerte en sus relatos parece, sin embargo, menos referida a la "búsqueda de esencias" de que ha hablado Rodríguez Monegal y más a una crítica de la hipocresía que ro. dea los cultos cristianos de velorios, condolencias, entierros y comentarios. Verdaderas anécdotas lindantes con lo jocoso respaldan los episodios macabros de "La última morada" o de algunos de los relatos que integran el volumen de cuentos Las bebidas azules. Pero en las tres primeras novelas de CMM la muerte se inviste con los papeles definitivos que marcan precisamente a los personajes. En El paredón es claro: Julio Calodoro está marcado por la muerte de su padre, la del soldado, la del vecino de su infancia, por la muerte que ve encarnada en la carpeta de asesinados del batistato y por el testimonio epistolar de Valtierra narrando un fusilamiento de "La Cabaña".

Tanto en Con las primeras luces como en La otra mitad el factor desencadenante de la trama es la muerte arrojada como una piedra en las quietas y falsamente limpias aguas de la realidad de los personajes. Los círculos concéntricos desenvueltos a su imperio no hacen sino medir su onda original. Mario Possenti decide reconstruir "la otra mitad" de Cora cuando ésta ha muerto suicidada o asesinada; Eugenio repasa su vida en tanto agoniza y al hacerlo recuerda las sucesivas muertes de la familia Escudero, con estremecidos capítulos en el caso de la tía Herminia y de la prima Mariucha.

Esa presencia de la muerte reflexionada en sus términos filosóficos. demistificada de todos los fastos o las hipócritas pompas de los cultos que la disfrazan, es muchas veces una muerte simbólica: la muerte del pasado, el fin de un mundo abolido por evolución, por el simple transcurso del tiempo y no necesariamente por la violencia revolucionaria. "La violencia está jugando en Cuba el papel que no puede suplir la madurez" decía en 1960 Martínez Moreno y en Con las primeras luces liquida por la "vejez" a un "mundo de oprimentes presencias muertas". 
Manejando cuatro generaciones (que van desde el General Escudero que participa en las campañas militares de la Guerra Grande, hasta sus bisnietos Roberto y Eugenio) CMM alcanza en Con las primeras luces una lograda visión de esa muerte por el tiempo a lo largo de unos cien años de historia uruguaya. El enfoque se centraliza en el llamado "patriciado uruguayo" (suette de aristocracia local) y cubre su auge, decadencia y aniquilamiento, al modo como lo ha novelado en Chile José Donoso. A partir de la coyuntura que ofrece la agonía de Eugenio (dada en seis monólogos en primera persona) se reconstruye el proceso de la familia Escudero narrado en treinta y dos capítulos escritos en tercera persona y deliberadamente enfriados por la distancia y el estilo.

El mayor auge de los Escudero se corresponde con la "edad heroica" que resume el general, registrándose en las generaciones que lo suceden, un acentuado proceso de decadencia que quizá alcanza su punto máximo con la muerte de la tía Herminia, nieta del General y madre de Roberto. Esta decadencia, esta "muerte" es integral: es social y política, tanto como económica y moral y habrá de desembocat en el aniquilamiento sanguíneo de los Escudero, anunciado con la muerte de Eugenio y con la única supervivencia familiar del invertido y solitario Roberto.

Carlos Martínez Moreno resume en esta novela las mejores virtudes de la novelística del 45: una lucidez militante puesta al servicio de la necesidad de efectuar una fría autopsia de la realidad, autopsia que efectúa no sin dolor pero que siente asociada a una forma de cambio impostergable. Esa lucidez está, sin embargo, impostada por un tono siempre acusatorio bajo cuya superficie puede descubrirse una "tensión" ética, una inestabilidad que es parte del propio "environment" en que vive hoy sumergido un atento escritor latinoamericano. Curiosamente, sobre ese dualismo permanente de las realidades enfrentadas se edifica otro: el que opone realidad y estilo. La obra de Martinez Moreno se conecta directamente a una trilogía de escritores - Flaubert, Borges y Camus- no necesariamente realistas. De ellos recibe la particular atención que prodiga a la cadencia y al ritmo de las palabras, a la elección pausada de los adjetivos, a la atención interior de cada frase. Pero en su caso, tratándose de una visión intelectualizada, el virtuosismo estilistico se revierte a términos conceptuales más que sensibles. Su dicción aparece sintetizada a términos notoriamente abrumados (especialmente en sus primeros relatos y en "Cordelia") y no hay comunicación afectiva de vivencias. Algo que Rodríguez Monegal saludara en su origen como "una saludable comezón estilística nacida del rigor verbal" se ha ido convirtiendo en una suerte de culteranismo medio jurídico, siempre racionalizado. 
Su temor -en el medio de las "tensiones" que hacen a su narrativa rica en sugestiones y siempre polarizada en términos dialécticamente opuestos- sigue siendo el que confesara irónicamente a un crítico en oportunidad de aparecer $E l$ paredón: el temor de caer en el "sentimentalismo que abre boquetes por los que se ven estropajosas entrañas vivas."

Macalester College

Fernando Ainsa Amigues

(Saint Paul, Minn.) 